Portland State University

PDXScholar

$11-22-2019$

\title{
Superhydrophobic Particle Ejections from Liquid Surfaces in Microgravity Environments
}

\author{
Elaina L. Gabriel \\ Portland State University
}

Follow this and additional works at: https://pdxscholar.library.pdx.edu/honorstheses

\section{Let us know how access to this document benefits you.}

\section{Recommended Citation}

Gabriel, Elaina L., "Superhydrophobic Particle Ejections from Liquid Surfaces in Microgravity Environments" (2019). University Honors Theses. Paper 800.

https://doi.org/10.15760/honors.818

This Thesis is brought to you for free and open access. It has been accepted for inclusion in University Honors Theses by an authorized administrator of PDXScholar. Please contact us if we can make this document more accessible: pdxscholar@pdx.edu. 
Superhydrophobic Particle Ejections from Liquid Surfaces in Microgravity Environments

by

Elaina Gabriel

An undergraduate honors thesis submitted in partial fulfillment of the

requirements for the degree of

Bachelor of Science

in

University Honors

and

Mechanical Engineering

Thesis Advisers

Mark Weislogel, PhD.

and

Lemmy Meekisho, PhD.

Portland State University 


\begin{abstract}
This paper explores a completely new avenue of microgravity fluidics that has not been systematically studied before, exploring superhydrophobic particle ejections from liquid surfaces in microgravity environments and quantifying the particle velocity varying particle. Superhydrophobic surfaces greatly reduce liquid-substrate contact. This allows for spontaneous ejection of floating particles in drop tower experiments. To quantify such phenomena, a drop tower experiment is constructed and tested. The Dryden Tower (DDT) is a laboratory facility at Portland State University that allows for the investigation of short duration exploration and research on Earth of 'micro-gravity' phenomena similar to that aboard orbiting spacecraft. Perhaps surprisingly, this short 2.1 second period of weightlessness during free fall provides ample time for many fluids, combustion, and materials science investigations. This study employs large superhydrophobic spherical particles of varying masses of the spheres to determine ejection velocities. Simple energy analysis is shown to provide fair agreement with the experimental results.
\end{abstract}

\title{
Introduction
}

In a recent article by Wollman et al. (2016), observations of "floating spheres" (a model of macrosurfactants), macro-scale particle injections, capture, and ejections were reported from drop tower tests. Additionally, puddle jumping from superhydrophobic substrates was demonstrated by Attari et el. (2016), where puddle jump limits, times, and velocities were reported as functions of fluid properties, wetting conditions, and relatively enormous puddle volumes. Such studies provide insight into the fundamental behaviors of large length scale capillary fluidic behavior. Applications of such phenomenon may be made to fluid systems aboard spacecraft (i.e. fuel tanks, coolants, and water processing). This study aims to demonstrate superhydrophobic particle ejection from liquid surfaces in the microgravity environment and quantify ejection velocity as a function of particle mass. The experiments are simple, where a Fig. 1 ping pong ball (particle) is coated with superhydrophobic treatment establishing contact angle $\theta \approx 150^{\circ}$. Such superhydrophobic surfaces repel water with low coefficients of friction. Masses are added to the ping pong ball by drilling in a hole in its top and gluing the mass to the inside bottom surface of the ball. The ball is then floated on the surface of the water bath, balanced, and released in the drop tower, the events are recorded via high-speed video camera. The short period of weightlessness during free fall provides ample 
time to observe the superhydrophobic 'particle' ejections from the liquid surface. The Dryden Tower (DDT) at Portland State University allows for the exploration for fluids, combustion, and materials science investigations (Wollman, 2013).

\section{Methodology}

The experiment drop tower rig is shown in Fig. 1. The camera is secured to mounts and bolted to the aluminum rig. The water bath is secured, levelled, and backlit by a diffuse light panel. To vary the mass of the ping pong ball, a hole was drilled into its top, and a weight glued inside. This method lowers the $20 \mathrm{~mm}$ OD the particle's center of gravity allowing for easy alignment of the sphere during testing. The spheres were coated with Cytonix aerosol spray resulting in a superhydrophobic substrate with contact angle $\theta \approx 150^{\circ}$. The superhydrophobic sphere with radius $R$ of $20 \mathrm{~mm}$ was placed and partially submerged in a tank of water as shown in Fig. 2 . With the camera recording, the drop capsule consisting of drag shield with the rig and experiment inside was released, retrieved, and video footage stored. Three spherical masses are tested, the results of which will be presented, following a brief review of a simplified analysis of the process.

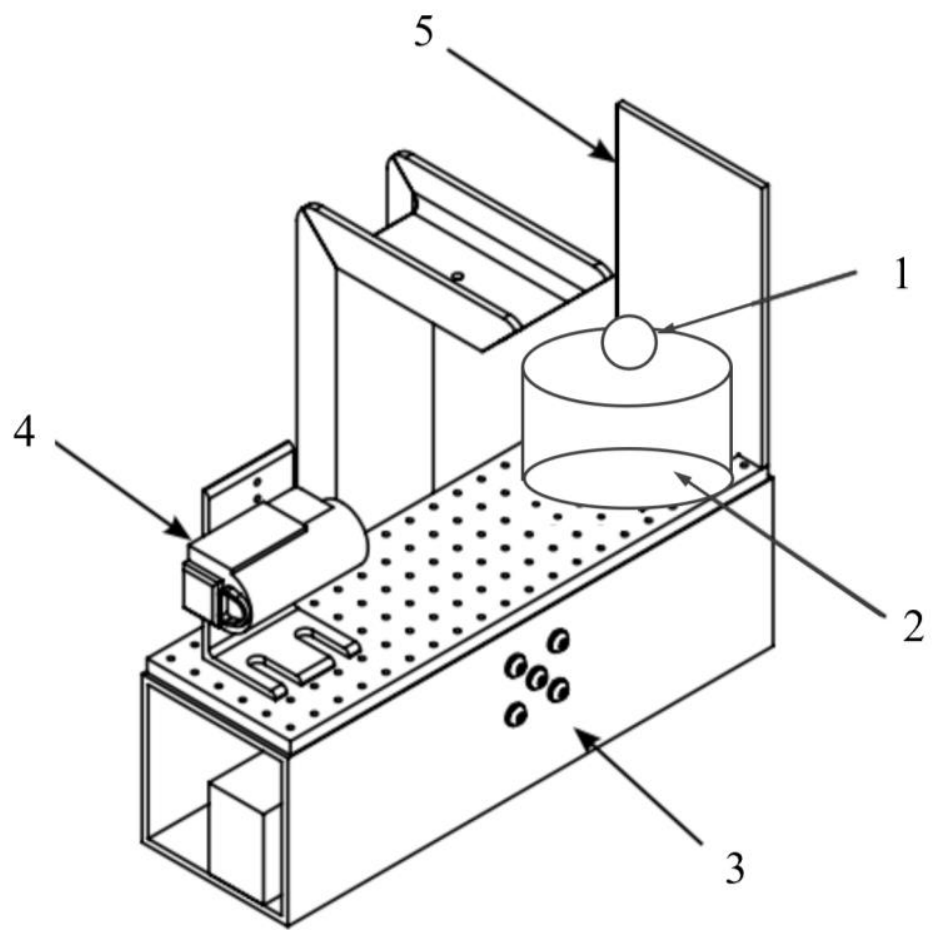

Fig. 1. Drop Tower experiment rig setup where the superhydrophobic particle (1) is centered in a liquid bath (2) is placed on the experiment rig (3) between the camera (4) and backlight (5). 

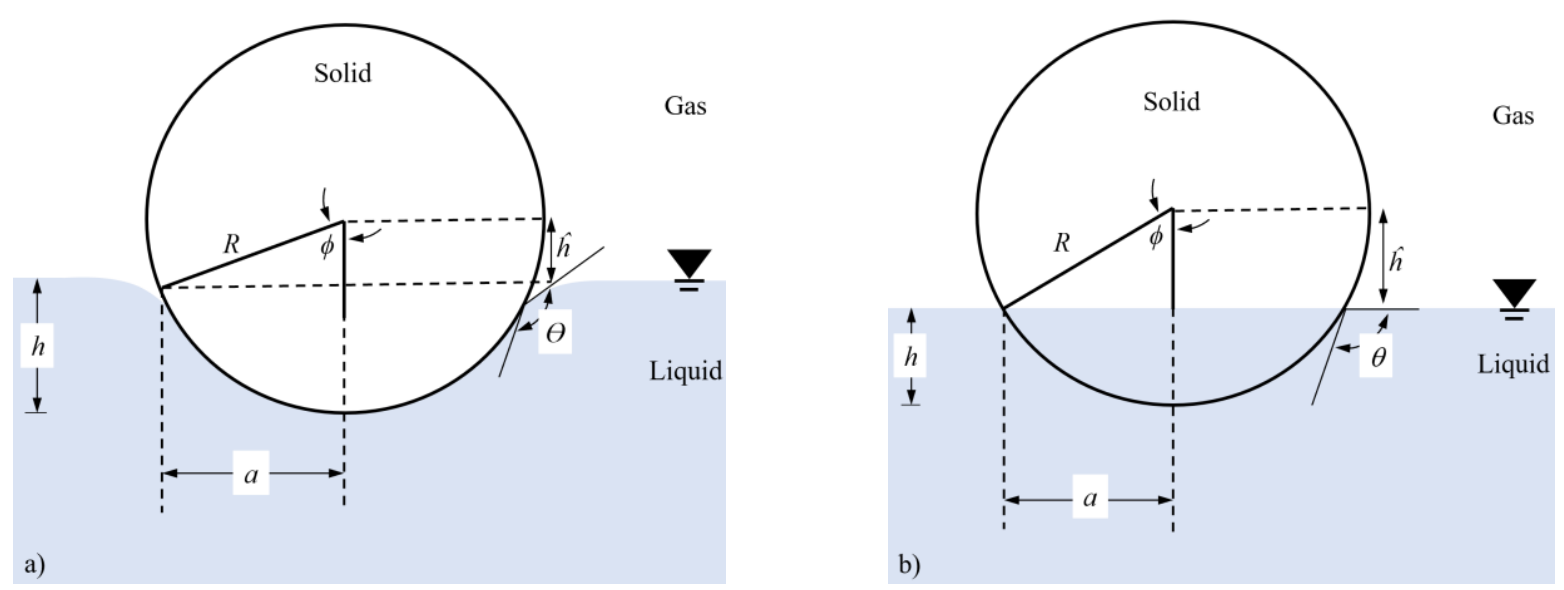

Fig. 2. a) Schematic of experiment geometry. The solid of radius $R$ is the superhydrophobic particle, submerged to depth $h$, with unsubmerged portion of radius $\hat{h}$, submerged area $a$, internal angle $\phi$, and contact angle $\theta$. b) Idealized schematic of experiment geometry.

\section{Energy Analysis}

Surface structure has a controlling influence at the three-phase contact line region where the interfacial parameters depend on the surface energies of the solid, liquid, and gas phases (Attari et al, 2016). A surface energy balance at initial and final state allows us to estimate particle ejection velocity. We follow conventional notation for: liquid-solid $l s$, gas-solid $g s$, liquid-gas $l g$, mass $m$ and particle radius $R$.

Applying a simple surface energy balance, the spherical particle's velocity $U$ is quickly predicted by equating the total surface energy of the initial state $E_{1}$ (static floating particle) with the total surface energy of the final energy state $\mathrm{E}_{2}$ (particle ejected at constant velocity $U$ ). The submerged height $h$ is a spherical cap depending on of the particle's radius $R$, volume of the particle $V$, mass $m$, and density of the water in the bath. Submerged heights for the experiments performed herein are listed in Table 1. From an energy standpoint, the energy before exiting the water must equal the energy as the sphere leaves the water; namely, $E_{1}=E_{2}$.

Table 1. Theoretical submerged depth $h$ of the superhydrophobic particle, average velocity $U_{\text {avg, }}$ and standard deviation.

\begin{tabular}{|r|r|r|r|}
\hline Mass (g) & $\begin{array}{c}\text { Submerged } \\
\text { Depth (m) }\end{array}$ & $\begin{array}{c}\text { U avg } \\
(\mathbf{c m} / \mathbf{s})\end{array}$ & $\begin{array}{c}\boldsymbol{U} \\
\text { St. dev. }\end{array}$ \\
\hline 27 & 0.029 & 6 & 0.22 \\
\hline 21 & 0.023 & 4.7 & 0.36 \\
\hline 19 & 0.22 & 6.55 & 0.19 \\
\hline
\end{tabular}


Such idealized initial and final states are depicted schematically in Fig. 4. The ejection velocity is the maximum velocity of the particle achieved the moment the particle detaches from the bath. The water in the bath is assumed ideal, with negligible dissipation, meeting the particle on a flat, infinite plane satisfying the contact angle condition $\theta$.

Thus, we have initial state

$$
E_{1}=(\sigma A)_{g s 1}+(\sigma A)_{l s 1}+(\sigma A)_{l g 1}+\frac{m U_{1}^{2}}{2}
$$

and final state

$$
E_{2}=(\sigma A)_{g s 2}+(\sigma A)_{l s 2}+(\sigma A)_{l g 2}+\frac{m U_{2}^{2}}{2} .
$$

Setting $E_{1}=E_{2}$ and solving for $U$ yields

$$
U=\left[-\left(\frac{2 \pi \sigma R^{2}}{m}\right)\left(1-\cos ^{2} \theta+\frac{2 h}{R} \cos \theta\right)\right]^{1 / 2}
$$
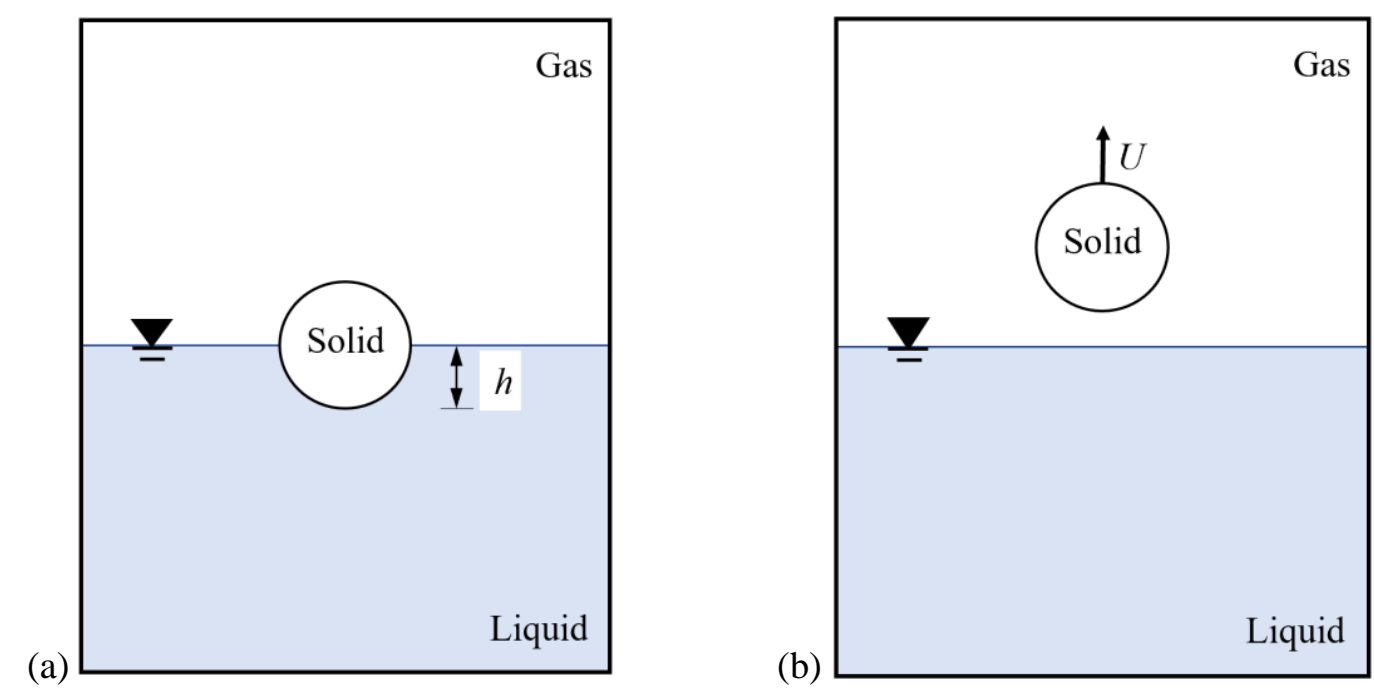

Fig. 4. Schematic of experiment energy states (a) $E_{1}$ and (b) $E_{2}$.

\section{Results}

The drop tests yielded a successful and consistent particle ejections from a liquid surface as shown in Fig. 5. The results are listed in Table 1. Prediction of the ejection velocity from equation (3) are listed in Table 2. Standard deviations and average velocities for each of the drop tests are in Table 1. Figure 7 depicts the velocities for each of the particles and their corresponding predicted velocities at a contact angle of $150^{\circ}$. Figure 8 depicts the velocities for each of the particles and 
their corresponding predicted velocities at a contact angle of $120^{\circ}$ which takes into account a decreased contact angle due to dynamic contact angle hysteresis. Position versus time for each of the drop tests are shown in Fig. 6 from which ejection velocities are easy to determine. Linear fits are used to establish average velocities with goodness of fit nearly equal to one.

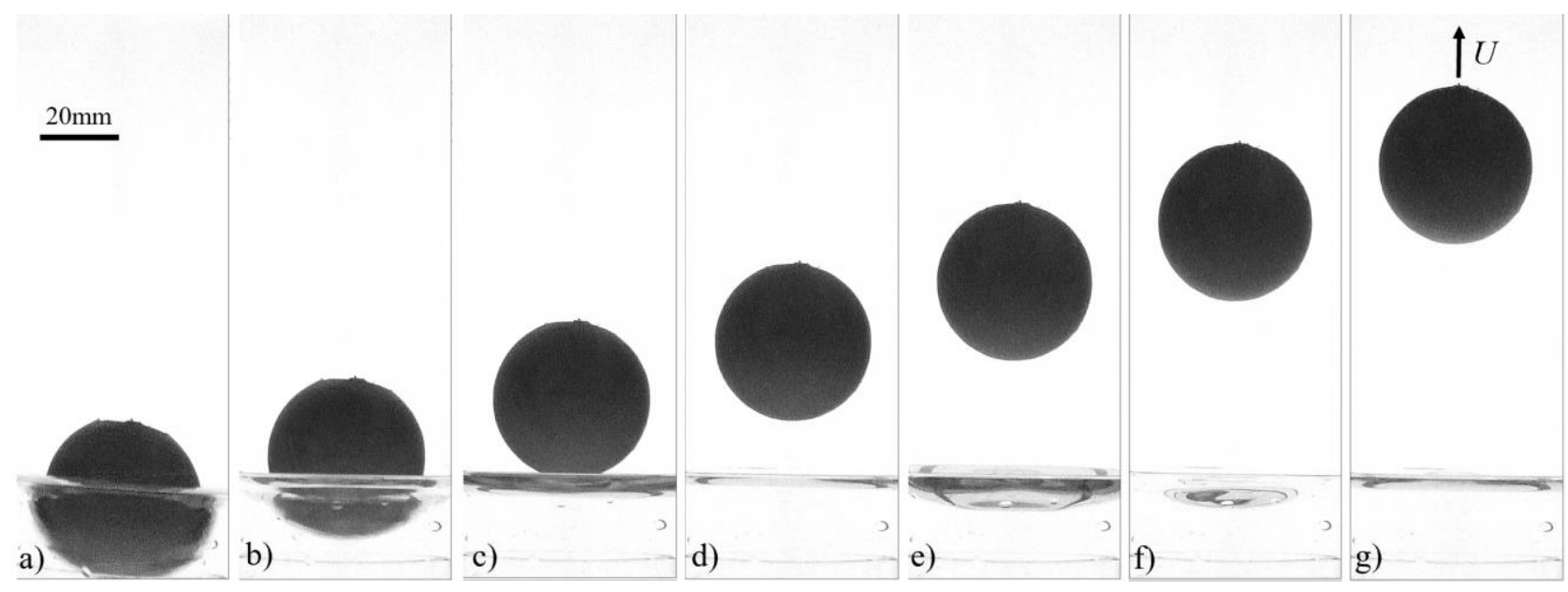

Fig. 5. Particle Ejection of a 27g , 20mm OD superhydrophobic sphere (Drop 08368) from a bath of water. Images were captured at $4 \mathrm{~Hz}$.

Table 2. Predicted velocities for the superhydrophobic particles with radius of $20 \mathrm{~mm} \mathrm{OD}$, and surface tension of $0.072 \mathrm{~N} / \mathrm{m}$ used.

\begin{tabular}{|r|c|c|c|}
\hline & \multicolumn{3}{|c|}{} \\
& \multicolumn{3}{|c|}{ Predicted Velocity (cm/s) } \\
\hline $\begin{array}{c}\text { Contact } \\
\text { Angle }\left(^{\circ}\right)\end{array}$ & $\mathbf{2 7 g}$ & $\mathbf{2 1 g}$ & $\mathbf{1 9 g}$ \\
\hline 155 & 0.128 & 0.125 & 0.131 \\
\hline 150 & 0.123 & 0.119 & 0.125 \\
\hline 145 & 0.117 & 0.112 & 0.118 \\
\hline 140 & 0.110 & 0.104 & 0.110 \\
\hline 135 & 0.101 & 0.095 & 0.100 \\
\hline 130 & 0.092 & 0.084 & 0.088 \\
\hline 125 & 0.081 & 0.071 & 0.074 \\
\hline 120 & 0.068 & 0.054 & 0.057 \\
\hline 115 & 0.051 & 0.030 & 0.031 \\
\hline 110 & 0.026 & 0.034 & 0.036 \\
\hline 105 & 0.036 & 0.056 & 0.059 \\
\hline 100 & 0.056 & 0.071 & 0.075 \\
\hline
\end{tabular}




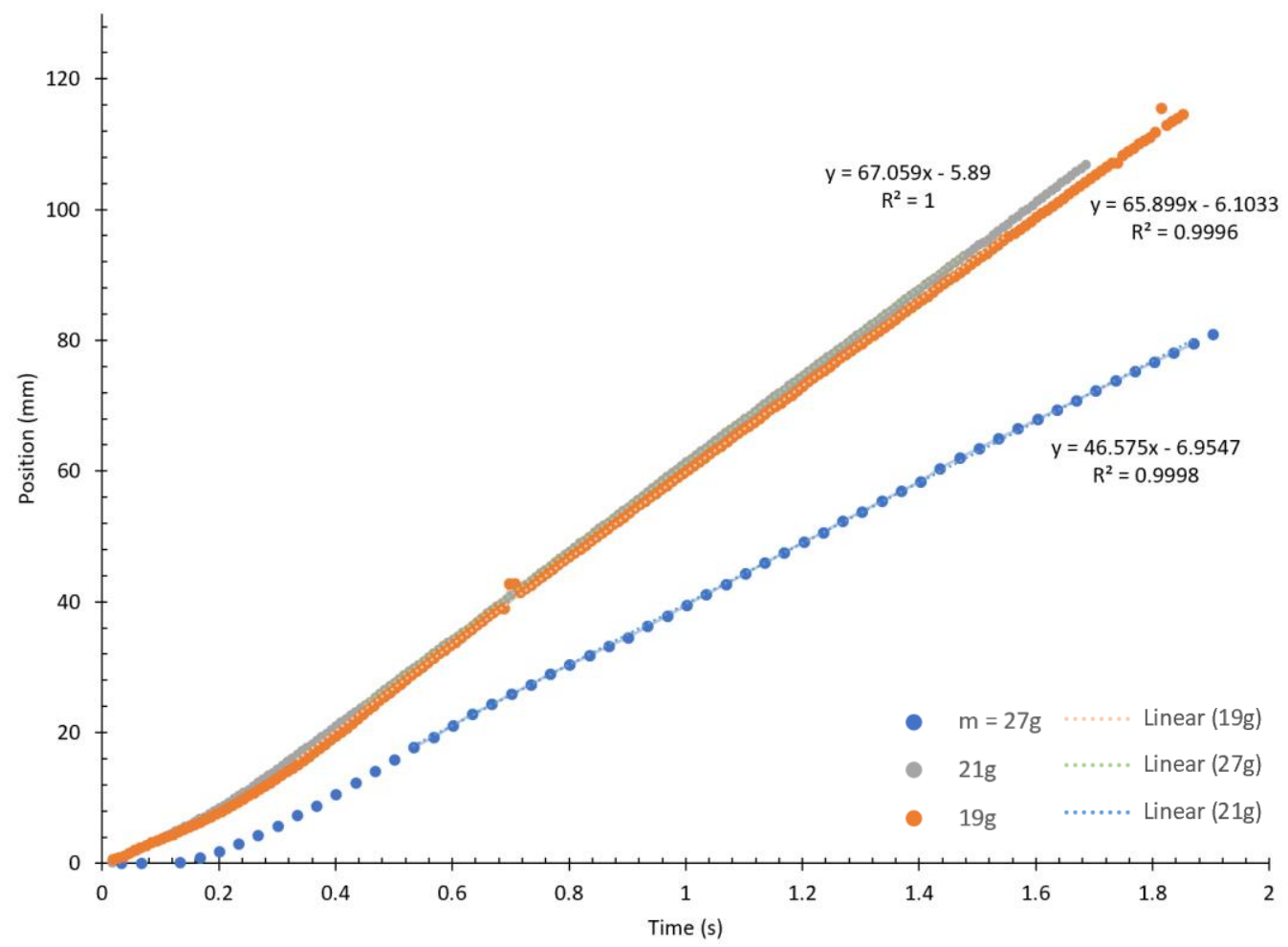

Fig. 6. Position (mm) versus time (s) for all particles with linear fit lines and r-squared values.

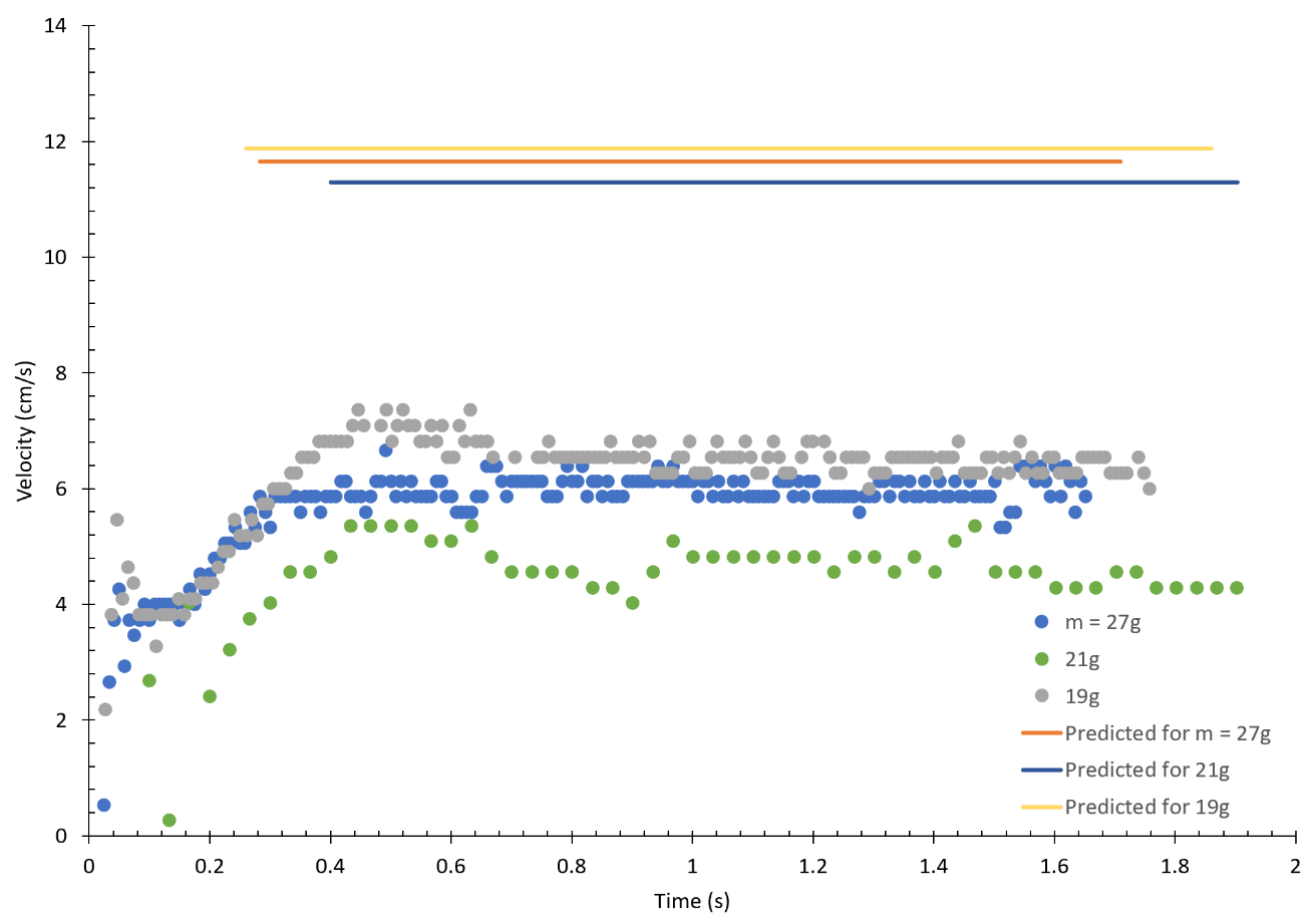

Fig. 7. Velocity $(\mathrm{cm} / \mathrm{s})$ versus time $(\mathrm{s})$ for all particles and their predicted velocity assuming a contact angle of $\left(\theta=150^{\circ}\right)$. 


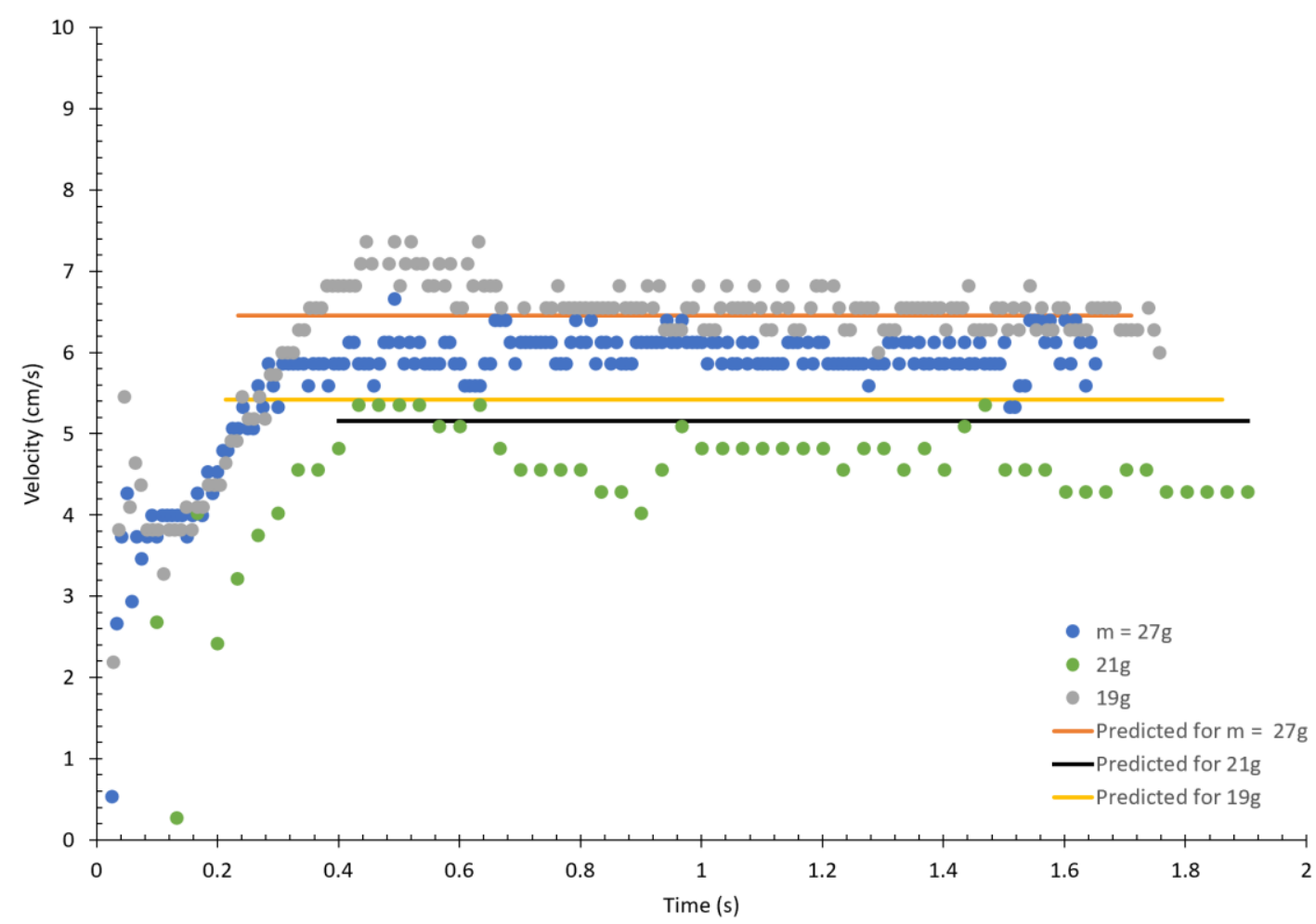

Fig. 8. Velocity $(\mathrm{cm} / \mathrm{s})$ versus time $(\mathrm{s})$ for all particles and their predicted velocity taking into account dynamic contact angle hysteresis with an effective contact angle of $\left(\theta=120^{\circ}\right)$.

\section{Conclusion}

A study quantifying superhydrophobic particle ejection velocity from liquid surfaces in microgravity environments is novel. This study exploits the particle's known geometry, and varies its mass to investigate its velocity. Terminal velocity is achieved once the sphere detaches from the bath. The predicted theoretical velocity accounting for a reduced contact angle due to dynamic contact angle hysteresis reveals a relationship between velocity and contact angle. A decreasing contact angle yields a decreasing predicted velocity as shown in Table 2.

All of the velocity predictions with the experimental data in Figs. 7 and 8 are due primarily to the neglect of free surface distortions and viscous contact line dissipation. The variation between the data points in Figs. 7 and 8 are one pixel. Discrepancies in experimental and analytical particle ejection velocities are due to neglect of surface nonuniformities, viscous dissipation, dynamic contact line dissipation, neglect of air properties, and the assumption that the water meets the particle on an infinite flat plane. Steady drop tests are shown in Fig. 6, with minimal anomalies. 


\section{References}

Attari et al.; Physics of Fluids 28, 102104 (2016); doi: 10.1063/1.4963686.

Wollman, A., Weislogel, M., Wiles, B., Pettit, D., \& Snyder, T. (2016). More investigations in capillary fluidics using a drop tower. Experiments in Fluids, 1-17. doi: 10.1007/s00348016-2138-4. 